\title{
CARBOIDRATOS NÃO ESTRUTURAIS E ACÚMULO DE FORRAGEM EM PASTAGENS DE Cynodon spp. SOB LOTAÇÃO CONTÍNUA
} \author{
Guilherme Silveira Pedreira² \\ ${ }^{1}$ Pós-Graduandos em Ciências Animal e Pastagens - USP/ESALQ. \\ ${ }^{2}$ Depto. de Produção Animal - USP/ESALQ, C.P. 9 - CEP: 13418-900 - Piracicaba, SP. \\ ${ }^{3}$ Bolsista FAPESP. \\ ${ }^{4}$ Bolsista CAPES \\ *Autor correspondente <scdsilva@carpa.ciagri.usp.br>
}

Carlos Augusto Brandão de Carvalho ${ }^{1,3}$; Sila Carneiro da Silva ${ }^{2 *}$; André Fischer Sbrissia ${ }^{1,3}$; Jaílson Lara Fagundes ${ }^{1}$; Roberta Aparecida Carnevalli' ${ }^{1}$; Luiz Felipe de Moura Pinto ${ }^{1,4}$; Carlos

RESUMO: Reservas orgânicas são compostos capazes de determinar o vigor e a velocidade da rebrota de plantas forrageiras influenciando sua persistência na pastagem. Dentre os compostos constituintes das reservas orgânicas estão os carboidratos não estruturais (CNE). Os teores e a quantidade de CNE foram avaliados em amostras de pastagens de 'Tifton-85', 'Florakirk' e 'Coastcross', estabelecidas em Nitossolo Vermelho eutroférrico, durante as estações de inverno, primavera e verão. Os tratamentos corresponderam a quatro situações de "steady state" do relvado, caracterizadas por alturas de pasto de 5, 10, 15 e $20 \mathrm{~cm}$ mantidas por ovinos sob regime de lotação contínua. O delineamento experimental foi em blocos completos casualizados, com um arranjo de parcelas subdivididas e quatro repetições. Os cultivares foram alocados nas parcelas e alturas de pasto nas subparcelas. As coletas das amostras para determinação de CNE foram realizadas mensalmente utilizando-se tubos de aço de $15 \mathrm{~cm}$ de diâmetro por $50 \mathrm{~cm}$ de altura. Os teores de CNE foram quantificados através de metodologia analítica baseada em digestão ácida e as taxas de acúmulo de matéria seca foram mensuradas através de gaiolas de exclusão. Os cultivares de Cynodon spp. avaliados apresentaram um padrão de variação sazonal quanto à prioridade de alocação de CNE para os órgãos de reserva (base do colmo e raízes). Os teores de CNE obtidos não atingiram níveis que pudessem ser considerados danosos à perenidade e à produtividade das pastagens de 'Tifton-85', 'Florakirk' e 'Coastcross'. 'Tifton-85' apresentou maior quantidade de CNE na base do colmo e raízes, o que poderia contribuir para uma maior tolerância a períodos de estresse.

Palavras-chave: Cynodon, carboidratos de reserva, teor, raízes, base do colmo

\section{NON STRUCTURAL CARBOHYDRATES AND HERBAGE ACCUMULATION IN Cynodon spp. SWARDS UNDER CONTINUOUS STOCKING}

\begin{abstract}
Organic reserves are chemical substances that may determine the vigour of regrowth of forage plants and may alter their persistence in grazed swards. Non structural carbohydrates (NEC) are among those substances. The concentration and the amount (pool) of total non structural carbohydrates were evaluated in samples of 'Tifton-85', 'Florakirk' and 'Coastcross' pastures, established on an Eutric Kandiudalf, during the winter, spring and summer. Treatments corresponded to four "steady state" sward conditions characterised by sward surface heights (SSH) of 5, 10,15 and $20 \mathrm{~cm}$ maintained by sheep under continuous stocking. The experimental design was a complete randomised block, with treatments arranged in split-plot with four replications. Grass cultivars were allocated to plots and SSH to sub-plots. Samples for determination of NEC were collected monthly using $15 \mathrm{~cm}$ diameter and $50 \mathrm{~cm}$ long steel tubes. NEC concentrations were determined by acid digestion and rates of dry matter accumulation were measured with exclosure cages. Cynodon spp. cultivars presented a seasonal pattern of variation related to the allocation of NEC in the stubble and roots. NEC concentrations did not reach limits that could be considered harmful to sward persistence and productivity. 'Tifton-85' presented the highest NEC pool for the stubble and root components and that could be an indication of a higher tolerance to periods of stress.
\end{abstract}

Key words: Cynodon, store carbohydrates, concentration, roots, branch aerial

\section{INTRODUÇÃO}

Os carboidratos de reserva armazenados em órgãos vegetativos de plantas forrageiras têm sido considerados por muitos pesquisadores como os recursos primários de reserva de energia para 0 crescimento de gramíneas perenes. Porém, Brougham (1956) constatou que a recuperação das plantas desfolhadas dependia da área foliar remanescente, uma vez que observou uma relação inversa entre a 
velocidade de recuperação da área foliar inicial e o grau de desfolha sofrido pela planta. Nas últimas décadas, trabalhos conduzidos com gramíneas tropicais têm mostrado que a produção de matéria seca, oriunda da rebrota avaliada 3 a 4 semanas após o corte, não é dependente do teor de carboidratos totais não estruturais (CNE) presente no momento do corte ou pastejo (Gomide et al., 1979; Jones \& Carabaly, 1981). Contudo, esses são essenciais para a sobrevivência e produção de novos tecidos durante os períodos nos quais a utilização dos carboidratos pelas plantas excede sua capacidade de suprimento através da fotossíntese (Smith, 1972; Rodrigues \& Rodrigues, 1987).

A produção e a concentração de carboidratos solúveis nos tecidos e órgãos das plantas são dependentes de muitos fatores, tais como aqueles ligados às condições de ambiente, ao estado nutricional e ao estádio fisiológico da planta (Reis et al., 1985; George et al., 1989; Soares Filho, 1991; Humphreys, 1991).

Os CNE frequentemente encontrados são os monossacarídeos glicose e frutose, os dissacarídeos sacarose e maltose e os polissacarídeos amido e frutosana (Smith, 1972). Esses açúcares possuem grande importância no metabolismo vegetal devido a participarem ativamente de vias metabólicas como metabólitos intermediários (Stryer, 1975). As gramíneas forrageiras originárias de países de clima tropical e subtropical acumulam principalmente amido, o qual pode ser encontrado nas formas de amilose e amilopectina (Smith \& Grotelueschem, 1966). Os CNE são considerados os componentes de reserva mais importantes de gramíneas forrageiras. No entanto, esses estão em equilíbrio com a reserva de compostos nitrogenados (N) solúveis (Smith, 1973). Provavelmente, esses açúcares podem ser mais rapidamente utilizados para a produção de novos tecidos vegetais quando 0 suprimento de $\mathrm{N}$ é adequado (Pedreira, 1995). A translocação de carboidratos para os rizomas é incrementada quando as taxas de fertilização de $\mathrm{N}$ são diminuídas (Adegbola \& McKel, 1966).

Já que o teor de CNE presente na base de colmos e raízes de gramíneas normalmente diminui após um período de crescimento intenso ou logo após o corte da base do colmo, esses compostos de reserva energética seriam utilizados para a produção de novos tecidos assim como para a manutenção da atividade respiratória de células e tecidos durante períodos de déficit energético (Bokhari, 1977; Botrel, 1980; Soares Filho, 1991). Dessa forma, o balanço entre CNE e compostos nitrogenados solúveis, estado fisiológico da planta e as condições de ambiente no período de desfolha determinariam, juntos, o potencial de produção de cada espécie forrageira numa dada localidade (Lemaire \& Agnusday, 1999).

Considerando-se a importância dos CNE para a perenidade e produtividade de gramíneas forrageiras utilizadas em pastagens, o objetivo deste trabalho foi avaliar os teores e a quantidade de CNE e as taxas de acúmulo de matéria seca de forragem em pastagens de Cynodon spp. durante as estações de inverno, primavera e verão.

\section{MATERIAL E MÉTODOS}

O experimento foi realizado na Unidade Experimental de Plantas Forrageiras (UEPF), em área do Departamento de Produção Animal da Escola Superior de Agricultura "Luiz de Queiroz", Universidade de São Paulo, município de Piracicaba, Estado de São Paulo, localizado a $22^{\circ} 42^{\prime} 30^{\prime \prime}$ de latitude sul, 47³8'00"de longitude oeste e $546 \mathrm{~m}$ de altitude (Ometto, 1989). O período experimental se estendeu de 22 de julho de 1998 a 10 de março de 1999, com duração de 231 dias.

\section{Pastagem e período experimental}

O experimento foi instalado em um Nitossolo Vermelho Eutroférrico, com horizonte A moderado, e textura argilosa/muito argilosa. Análise realizada ao início da implantação da área experimental revelou $\mathrm{pH}\left(\mathrm{CaCl}_{2}\right)=$ 5,4; M.O. $\left(\mathrm{g} \mathrm{kg}^{-1}\right)=37,0 ; \mathrm{P}\left(\mathrm{mg} \mathrm{dm}^{-3}\right)=99 ; \mathrm{K}\left(\mathrm{mmol}_{\mathrm{c}}\right.$ $\left.\mathrm{dm}^{-3}\right)=4,6 ; \mathrm{Ca}\left(\mathrm{mmol}_{\mathrm{cm}} \mathrm{dm}^{-3}=75,0 ; \mathrm{Mg}\left(\mathrm{mmol}_{\mathrm{c}} \mathrm{dm}^{-3}\right)=26,0\right.$; $\mathrm{H}+\mathrm{Al}\left(\mathrm{mmol}_{\mathrm{c}} \mathrm{dm}^{-3}\right)=30,0 ; \mathrm{SB}\left(\mathrm{mmol}_{\mathrm{c}} \mathrm{dm}^{-3}\right)=105,6$; $\mathrm{T}\left(\mathrm{mmol}_{\mathrm{c}} \mathrm{dm}^{-3}\right)=135,6 ; \mathrm{V}(\%)=77,9$. Devido à alta fertilidade não foram realizadas práticas de calagem no momento da implantação ou durante o experimento.

Os pastos foram implantados em março de 1996 através de mudas, sendo que, devido a adversidades climáticas e ao baixo percentual de pegamento das mudas, fez-se o replantio de algumas parcelas durante os meses de fevereiro e março de 1997. Ao longo de 1997 foram fertilizados com $150 \mathrm{~kg} \mathrm{~N}^{-1}$ na forma de sulfato de amônio. Em 1998 receberam uma adubação com 40 $\mathrm{kg} \mathrm{N} \mathrm{ha}^{-1}$ na forma de sulfato de amônio em janeiro e outra em julho. Um corte de uniformização foi realizado em março de 1998 a uma altura de cerca de $3 \mathrm{~cm}$ do nível do solo. Os animais foram adicionados às unidades experimentais (UE) à medida que as alturas desejadas do relvado eram atingidas (a partir de maio). Durante a condução do experimento foram realizadas quatro adubações nitrogenadas utilizando como fonte de nitrogênio 0 sulfato de amônio. A primeira foi realizada em 19 de setembro (40 kg N ha-1), a segunda em 21 de outubro (50 $\left.\mathrm{kg} \mathrm{N}^{-1}\right)$, a terceira em 7 de dezembro $\left(25 \mathrm{~kg} \mathrm{~N}^{-1}\right)$ e a quarta em 7 de março $\left(75 \mathrm{~kg} \mathrm{~N}^{-1}\right)$. As quantidades de fertilizante aplicadas foram calculadas a fim de que fosse conseguido um acúmulo mínimo de forragem suficiente para manter pelo menos dois animais por unidade experimental durante todo o período de avaliação.

\section{Condições climáticas}

Conforme o sistema Köppen, o clima da região de Piracicaba pode ser classificado como Cwa, isto é, mesotérmico úmido, subtropical de inverno seco, onde a temperatura do mês mais frio é inferior a $18^{\circ} \mathrm{C}$ e a do 
mês mais quente ultrapassa os $22^{\circ} \mathrm{C}$ (Brasil, 1960). Os dados climáticos referentes ao período experimental encontram-se na TABELA 1. Estes foram obtidos no Posto Meteorológico do Departamento de Ciências Exatas da ESALQ-USP, localizado cerca de $500 \mathrm{~m}$ da área experimental.

\section{Delineamento e manutenção das condições experimentais}

O delineamento experimental utilizado foi blocos completos casualizados com quatro repetições em um arranjo de parcelas subdivididas "split-plot". Os cultivares de Cynodon spp. (Tifton-85, Florakirk e Coastcross). foram submetidos a quatro condições de pasto caracterizadas pelas alturas de 5, 10, 15 e $20 \mathrm{~cm}$ em relação ao nível do solo, mantidas "constante" através do pastejo por ovinos em regime de lotação contínua e taxa de lotação variável. Cada UE possuía cerca de 400 $\mathrm{m}^{2}$ e a área experimental total cerca de 2 ha. A altura média dos pastos foi monitorada semanalmente através da tomada de 20 leituras em cada unidade experimental com o prato ascendente duas vezes por semana. Uma vez ao mês era feita a calibração da altura comprimida do pasto com a altura não comprimida (régua - altura base do tratamento), gerando-se dessa forma o valor da altura usado como referência para o monitoramento dos tratamentos.

\section{Calibração: altura x massa}

Uma vez ao mês foi elaborada uma equação de calibração entre altura e massa de forragem com a finalidade de relacionar a altura média do pasto com a massa de forragem existente na pastagem, bem como para o cálculo do acúmulo de matéria seca. Para esta calibração foram escolhidos dois pontos de cada unidade experimental, sendo estes correspondentes àqueles de maior e menor altura, a fim de se obterem as maiores amplitudes possíveis de massa de forragem. As medidas com régua e prato ascendente foram tomadas dentro de um círculo com $0,25 \mathrm{~m}^{2}$ de área, colocado em cada ponto previamente escolhido. Em seguida a forragem era cortada no nível do solo (utilizando-se tosquiadeira elétrica para ovinos), lavada para eliminação de resíduos de terra e fezes, seca em estufa a $65^{\circ} \mathrm{C}$ até massa constante e pesada. Assim, depois de determinada a massa seca, era estabelecida, através de regressão linear, a relação entre altura do pasto e massa de forragem, para cada mês, para cada cultivar. A partir da obtenção das equações de calibração foi possível calcular as massas de forragem presentes em cada período de avaliação e o acúmulo de forragem a partir da altura do relvado.

\section{Coleta e processamento das amostras}

As amostragens foram realizadas com o objetivo de coletar os tecidos vegetais da base do colmo e raízes (raízes e rizomas) visto serem os componentes morfológicos que acumulam a quase totalidade dos CNE. Foram coletadas amostras segundo um intervalo médio de quatro semanas, iniciando-se em julho/98 com

TABELA 1 - Temperaturas médias mensais do ar (máxima média, mínima média e média), precipitação pluvial e insolação diária média durante o período experimental (de agosto/98 a março/99) e valores médios para os últimos 80 anos.

\begin{tabular}{|c|c|c|c|c|c|}
\hline \multirow{2}{*}{ Mês/ano } & \multicolumn{3}{|c|}{ Temperatura } & \multirow{2}{*}{$\begin{array}{l}\text { Precipitação } \\
\text { Média }\end{array}$} & \multirow{2}{*}{$\begin{array}{c}\text { Insolação } \\
\text { Média }\end{array}$} \\
\hline & Máxima média & Míni ma média & Média & & \\
\hline & 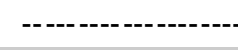 & $-1-{ }^{\circ} \mathrm{C}-\cdots-\cdots$ & ------------ & $\mathrm{mm}$ & $\mathrm{h} \mathrm{dia}^{-1}$ \\
\hline agosto/98 & 27,40 & 14,36 & 20,88 & 21,80 & 6,22 \\
\hline Média (80 anos - agosto) & 27,31 & 10,95 & 19,13 & 29,40 & 8,14 \\
\hline setembro/98 & 27,65 & 15,29 & 21,47 & 89,30 & 5,68 \\
\hline Média (80 anos - setembro) & 28,06 & 13,35 & 20,70 & 63,30 & 6,83 \\
\hline outubro/98 & 27,06 & 16,33 & 21,70 & 183,10 & 5,43 \\
\hline Média (80 anos - outubro ) & 28,90 & 15,57 & 22,23 & 111,28 & 6,87 \\
\hline novembro/98 & 30,04 & 16,45 & 23,24 & 26,60 & 7,79 \\
\hline Média (80 anos - novembro) & 29,57 & 16,68 & 23,09 & 130,01 & 7,42 \\
\hline dezembro/98 & 30,01 & 19,21 & 24,61 & 292,60 & 6,06 \\
\hline Média (80 anos - deze mbro) & 29,61 & 18,15 & 23,87 & 200,16 & 6,58 \\
\hline janeiro/99 & 31,42 & 18,98 & 25,20 & 210,80 & 7,70 \\
\hline Média (80 anos - janeiro) & 29,96 & 18,19 & 24,05 & 142,45 & 6,84 \\
\hline fevereiro/99 & 30,73 & 20,05 & 25,41 & 198,30 & 5,37 \\
\hline Média (80 anos - fevereiro) & 30,23 & 19,02 & 24,61 & 185,89 & 6,54 \\
\hline março/99 & 31,42 & 18,98 & 25,20 & 210,80 & 7,70 \\
\hline Média (80 anos - março) & 29,96 & 18,19 & 24,05 & 142,45 & 6,84 \\
\hline
\end{tabular}

Fonte: Arquivos do Departamento de Ciências Exatas - ESALQ/USP (1999).

Scientia Agricola, v.58, n.4, p.667-674, out./dez. 2001 
término em março/99. As amostragens foram sempre que possível realizadas no período matinal (das 7h00 às 10h00). Em cada avaliação a amostragem foi realizada através da retirada e reunião de três subamostras por UE. Para tanto foram utilizados tubos cilíndricos de aço de $50 \mathrm{~cm}$ de comprimento e $15 \mathrm{~cm}$ de diâmetro. Estes eram inicialmente colocados em pontos previamente mensurados e marcados da UE segundo a altura de pasto definida para cada tratamento. Em seguida os tubos eram cravados no solo até uma profundidade de aproximadamente $15 \mathrm{~cm}$ utilizando-se, para tanto, marretas de $8 \mathrm{~kg}$. As sub-amostras retiradas dos tubos eram então padronizadas a uma altura de $10 \mathrm{~cm}$ a partir da superfície do solo, utilizando-se ferramenta de corte. As três subamostras retiradas por UE eram acondicionadas juntas em um saco plástico resistente, identificadas e rapidamente encaminhadas a uma câmara fria, cuja temperatura era de $-5^{\circ} \mathrm{C}$.

A base do colmo de cada sub-amostra era então padronizada a uma altura de $5 \mathrm{~cm}$ a partir da superfície do solo, utilizando-se, para tanto, uma tosquiadeira elétrica de ovinos. A seguir, a porção aérea era então cortada no nível do solo, colocada em bandeja de alumínio juntamente com as demais subamostras e colocada em estufa de ventilação forçada com uma temperatura de $105^{\circ} \mathrm{C}$ durante uma hora, para inibição das atividades enzimática e respiratória das células. Após esse período, a mesma estufa era regulada a uma temperatura de $65^{\circ} \mathrm{C}$, onde as amostras permaneciam por 72 horas. As amostras eram então retiradas e pesadas em balança eletrônica após 15 minutos (equilíbrio hídrico).

As raízes e/ou rizomas foram separadas do solo através de lavagens sucessivas em peneiras com malha de $5 \mathrm{~mm}$ até que não fosse mais possível se identificar qualquer contaminação com solo. Logo a seguir as subamostras de raiz da mesma amostra eram colocadas em uma mesma bandeja, destinadas à estufa de ventilação forçada e pesadas de forma idêntica àquela descrita para a base do colmo.

As amostras de base do colmo e raízes foram então moídas separadamente em moinhos tipo Willey utilizando-se peneiras de $1 \mathrm{~mm}$, acondicionadas em recipientes plásticos, identificadas e armazenadas. Assim, cada tratamento possuía uma amostra de base do colmo e outra de raízes.

\section{Análise química dos $\mathrm{CNE}$}

Para análise química dos CNE foi utilizado o método inicialmente descrito por Smith (1969) e adaptado pelo Laboratório de Nutrição Animal da Universidade Federal de Viçosa (Silva, 1990). Devido à contaminação variável de solo nas amostras armazenadas, a concentração de CNE foi expressa com base na matéria orgânica.

\section{Acúmulo de forragem}

O acúmulo de forragem foi estimado utilizando- se 3 gaiolas de exclusão, por UE, compreendendo uma área de aproximadamente $0,5 \mathrm{~m}^{2}(0,7 \mathrm{~m} \times 0,7 \mathrm{~m})$ e $0,7 \mathrm{~m}$ de altura cada, e observando-se um intervalo de 21 dias entre amostragens sucessivas. Após a amostragem, as gaiolas eram rotacionadas nas unidades experimentais e fixadas em novos pontos representativos da condição (altura média) do posto no momento do rodízio. Os valores foram estimados segundo o método agronômico da diferença, conforme a equação de Davies et al. (1993): $\mathrm{AF}=\mathrm{MFf}-\mathrm{MFi}$, onde: $\mathrm{AF}=$ acúmulo de forragem; $\mathrm{MFf}=$ massa de forragem sob a gaiola, no último dia da exclusão (dia 21); $\mathrm{MFi}=$ massa de forragem na unidade experimental no dia da colocação das gaiolas (dia 0).

\section{Análise estatística}

Os dados foram analisados utilizando-se o procedimento GLM (General Linear Models) do pacote estatístico SAS (Statistical Analysis System), versão 6.12 para Windows. Dentro deste procedimento, optou-se pelo subprocedimento de medidas repetidas no tempo (Repeated Measures), uma vez que todas as variáveis em estudo foram coletadas ao longo de oito meses (SAS Institute, 1988). Dessa forma foi possível detectar-se os efeitos das causas de variação principais (bloco, cultivar e altura), as interações entre elas (bloco x cultivar, bloco $x$ altura, cultivar $x$ altura), além dos efeitos de tempo dentro de cada uma das causas de variação principais (tempo, tempo $\mathrm{x}$ bloco, tempo $\mathrm{x}$ cultivar; tempo $\mathrm{x}$ altura; tempo $\mathrm{x}$ cultivar $\mathrm{x}$ altura).

Todos os conjuntos de dados foram testados, antes da análise geral global, com a finalidade de assegurar que as quatro prerrogativas básicas da análise de variância (aditividade do modelo, independência dos erros, normalidade dos dados e homogeneidade das variâncias) estavam sendo respeitadas. Utilizou-se o "LSMEANS" para comparação de médias entre tratamentos.

\section{RESULTADOS E DISCUSSÃO}

A avaliação de carboidratos totais não estruturais (CNE) foi feita levando-se em consideração tanto os teores como as quantidades na base do colmo $(5 \mathrm{~cm}$ acima do nível do solo) e das raízes $(10 \mathrm{~cm}$ de profundidade).

\section{Teores de CNE na base do colmo e nas raízes}

Foram observados efeitos de mês do ano $(P=0,0001)$ e cultivar $(P=0,0155)$ (Figura 1). Nas raízes houve efeito de mês do ano $(P=0,0001)$ e interação mês do ano x cultivar (Figura 1). Os maiores valores médios verificados para os teores de CNE na base do colmo ocorreram durante os meses referentes ao período de inverno $(10,35 \%)$, seguidos por aqueles de primavera $(7,05 \%)$ e, finalmente, os menores durante o verão $(5,0 \%)$ (Figura 1). O decréscimo nos valores de CNE ao longo das estações do ano deveu-se, provavelmente, à melhoria das condições climáticas verificadas ao longo 
dos meses de primavera e verão, as quais proporcionaram maiores taxas de acúmulo de matéria seca (TABELA 4) que, por sua vez, demandaram maior suprimento de reservas orgânicas a fim de constituírem novos tecidos (Reis et al., 1985; George et al., 1989). Andrade \& Marques Neto (1989) e Soares Filho (1991) também verificaram maiores teores de CNE no período de inverno para Brachiaria decumbens. No entanto, Dunn \& Nelson (1974) observaram uma diminuição nos teores de CNE nesse mesmo período em capim bermuda na região norte dos Estados Unidos (Missouri). Essas contradições verificadas nas variações sazonais nos teores de CNE podem ser explicadas pelo fato de que plantas vegetando em condições de inverno rigoroso permanecem cobertas pela neve necessitando, dessa forma, respirar o carboidrato armazenado a fim de garantir as funções vitais de suas células e, consequentemente, sua sobrevivência durante os períodos em que não possuem área foliar. Já em condições tropicais, as plantas normalmente apresentam área foliar durante todo o período de inverno de tal forma que o processo fotossintético continua ocorrendo. No entanto, como outros fatores climáticos como temperatura, luminosidade e pluviosidade são limitantes, o crescimento fica paralisado e os fotossintetados produzidos são armazenados.

Apesar de ter sido observada diferença entre cultivares em apenas dois meses de avaliação (setembro e outubro) $(P<0,05)$, os cultivares 'Tifton-85' e 'Coastcross' apresentaram valores de CNE superiores àqueles de 'Florakirk' durante 7 dos 9 meses avaliados (Figura 1). Este padrão de comportamento provavelmente deveu-se a eventos distintos que ocorreram com os cultivares que apresentaram os maiores valores. Devido ao consistente maior índice de área foliar apresentado por 'Tifton-85' em relação aos demais cultivares (Fagundes et al., 1999), possivelmente este cultivar também apresentou maior produção de

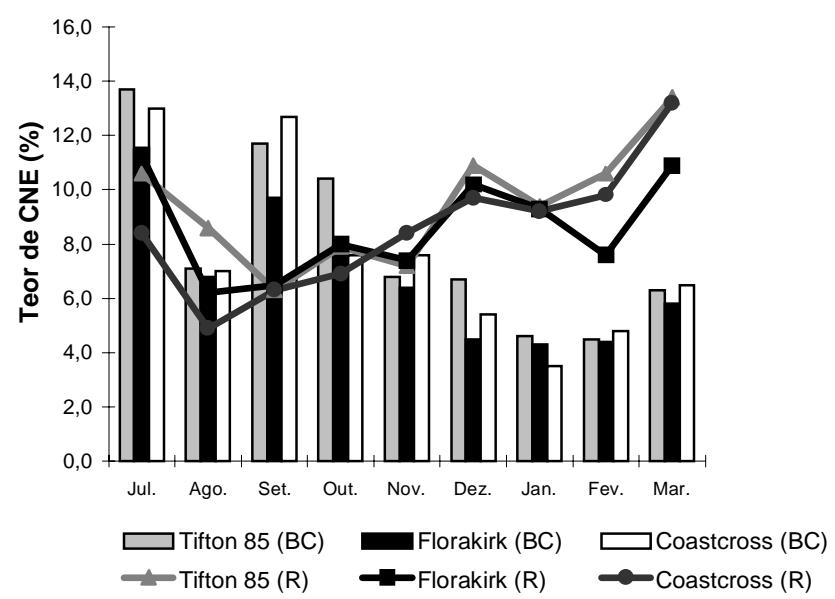

Figura 1 - Distribuição dos teores de CNE na base do colmo (BC; colunas) e nas raízes ( $R$; linhas) para os cultivares 'Tifton85', 'Florakirk' e 'Coastcross' de Julho de 1998 a Março de 1999.

Scientia Agricola, v.58, n.4, p.667-674, out./dez. 2001 fotossintetizados. A partir da síntese, os fotoassimilados podem ser destinados tanto para crescimento como para órgãos de reserva (Bokhari, 1977). Considerando que não houve diferença entre cultivares e quanto às taxas de acúmulo de forragem (TABELA 4), estes metabólitos foram provavelmente estocados nos órgãos de reserva desse cultivar, resultando em valores maiores. Já o cultivar 'Coastcross' possivelmente apresentou valores superiores ao 'Florakirk' devido priorizar a alocação de carboidratos para a base do colmo em relação às raízes durante as estações de inverno e primavera (Figura 1), em função de não apresentar rizomas, como os demais cultivares (Maraschin, 1996).

Os teores de CNE nas raízes aumentaram a partir de meados da primavera (novembro) superando aqueles observados na base do colmo desse período em diante (Figura 1). Esse padrão de comportamento sugere que os diferentes cultivares possuem variações sazonais quanto à alocação preferencial de fotoassimilados para seus diferentes órgãos de reserva. Possivelmente, isso indica a existência de um mecanismo que as plantas utilizam para garantir sua sobrevivência durante 0 período de inverno, bem como uma preparação para o florescimento, evento fenológico que demanda um grande suprimento energético (Smith, 1972). Além disso, a redução nos valores de CNE na base do colmo, concomitante ao aumento dos mesmos nas raízes deveu-se, provavelmente, à utilização dessas reservas para o crescimento das plantas, já que durante esse período foram verificadas as maiores taxas de acúmulo (TABELA 4).

Não foram verificadas variações nos teores de CNE em relação às alturas de relvado estudadas, tanto para a base do colmo quanto para as raízes. Isto se deveu, possivelmente, ao fato de que a menor altura de pasto estudada $(5 \mathrm{~cm})$ não foi drástica o suficiente para promover uma redução nos teores de carboidrato em relação às demais. Os dados de Fagundes et al. (1999) mostram que mesmo na altura de pasto mais baixa (5 $\mathrm{cm})$ havia interceptação luminosa suficiente para assegurar um suprimento mínimo de carbono para o metabolismo da planta, sem a necessidade de mobilização de suas reservas. Andrade \& Marques Neto (1989) também não observaram variações nos teores de CNE para Brachiaria decumbens em três intensidades de pastejo $\left(1,0,1,5\right.$ e 2,0 UA ha $\left.{ }^{-1}\right)$. Contudo, desfolhas mais intensas e frequentes normalmente promovem menores teores de CNE na planta (May, 1960), conforme pode ser amplamente verificado na literatura (Paula et al., 1969; Gross, 1988; Weinmann, 1961).

\section{Quantidade de CNE na base do colmo e nas raízes}

Foram verificados efeitos de cultivar ( $P=0,0001)$, altura $(P=0,0032)$, interação cultivar $x$ altura $(P=0,0127)$ $e$ interação mês de ano $x$ altura $(P=0,0006)$ (TABELAS 2 e 3), enquanto que para as raízes foram observados apenas efeitos de cultivar $(P=0,0001)$ e mês do ano 
( $\mathrm{P}=0,0001)$. O cultivar 'Tifton-85' apresentou os maiores valores de CNE na base do colmo, seguido de 'Florakirk' e 'Coastcross' (TABELA 2). Para as raízes o comportamento foi semelhante com o cultivar 'Tifton-85' apresentando uma média, durante o período

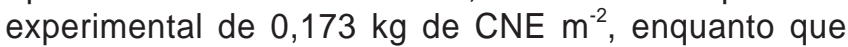
'Florakirk' e 'Coastcross' apresentaram durante o mesmo período uma média de 0,106 e $0,073 \mathrm{~kg}$ de $\mathrm{CNE} / \mathrm{m}^{2}$, respectivamente. A quantidade de CNE nas raízes esteve diretamente relacionada com a quantidade de raízes existentes. Assim, maiores massas de raízes determinaram as maiores quantidades de CNE. Este fato é consistente com a morfologia de cada cultivar, ou seja, 'Tifton-85' é o cultivar que possui a maior quantidade de rizomas grandes, 'Coastcross' a menor quantidade de rizomas pequenos e 'Florakirk' assume uma posição intermediária. Já na base do colmo os maiores valores observados para 'Tifton-85' podem estar associados tanto aos maiores teores de CNE (Figura 1) em relação à 'Florakirk', quanto à maior densidade de forragem quando comparado com 'Florakirk' e 'Coastcross' (Carnevalli, 1999). Essas maiores densidades foram decorrentes de maiores densidades populacionais de perfilhos verificadas para 'Tifton-85'em relação aos demais (Carvalho, 2000) em qualquer das alturas de pasto estudadas.

Os resultados de quantidade de CNE nas raízes apresentados em relação às alturas de pasto seguiram um padrão semelhante àquele demonstrado para os teores, indicando, mais uma vez, que os tratamentos de desfolhas mais intensas não foram capazes de promover uma diminuição na massa de raízes. Já para a base do colmo, os valores da quantidade de CNE em relação às alturas de pasto e aos cultivares não apresentaram um comportamento homogêneo ao longo do período experimental, justificando as interações observadas para essa variável (TABELA 3). As constantes mudanças na classificação das médias referentes às alturas deveramse, provavelmente, ao florescimento heterogêneo verificado para os cultivares 'Florakirk'e 'Coastcross' (Carvalho, 2000), o qual promoveu variações nos valores de massa por perfilho (Sbrissia, 2000) e em densidade populacional de perfilhos (Carvalho, 2000) refletindo, dessa forma, em valores de biomassa variáveis ao longo dos meses (Sbrissia, 2000) que, por sua vez, determinaram as diferenças nas quantidades de CNE.

\section{Taxas de acúmulo de forragem}

Para acúmulo de forragem foram verificados efeitos de mês do ano $(P=0,0001)$ e interação mês do ano $x$ cultivar $(P<0,05)$. De forma geral, os dados mostraram uma menor taxa de acúmulo para o cultivar 'Florakirk', com 'Tifton-85' e 'Coastcross' apresentando, na maior parte dos meses, os maiores valores observados (TABELA 4). Observando-se a mesma tabela, nota-se o padrão estacional de produção de forragem, onde nos meses de primavera e verão foram verificados valores superiores àqueles referentes ao período de inverno. Houve redução de produção no mês de novembro devido a uma forte estiagem ocorrida naquele período (TABELA 1). Apesar disso, os valores absolutos obtidos revelaram taxas de acúmulo de forragem compatíveis com a obtenção de altas taxas de lotação e, conseqüentemente, ganhos por hectare elevados. Tal fato foi confirmado por Carnevalli (1999)

TABELA 2 - Quantidade de CNE na base do colmo de três cultivares de Cynodon spp., de julho/98 a março/ 99.

\begin{tabular}{lccccc}
\hline Mês & Tifton 85 & Florakirk & Coastcross & Média & EPM \\
\hline Julho & $0,228^{a}$ & $0,137^{b}$ & $0,127^{b}$ & 0,171 & 0,016 \\
Agosto & $0,256^{a}$ & $0,173^{b}$ & $0,138^{c}$ & 0,189 & 0,009 \\
Setembro & $0,385^{a}$ & $0,169^{b}$ & $0,148^{b}$ & 0,234 & 0,035 \\
Outubro & $0,279^{a}$ & $0,219^{b}$ & $0,153^{c}$ & 0,217 & 0,009 \\
Novembro & $0,229^{a}$ & $0,215^{a}$ & $0,165^{b}$ & 0,203 & 0,012 \\
Dezembro & $0,239^{a}$ & $0,220^{a}$ & $0,163^{b}$ & 0,207 & 0,011 \\
Janeiro & $0,232^{a}$ & $0,194^{a}$ & $0,133^{b}$ & 0,186 & 0,018 \\
Fevereiro & $0,207^{a}$ & $0,165^{b}$ & $0,121^{c}$ & 0,164 & 0,014 \\
Março & $0,171^{a}$ & $0,160^{a}$ & $0,114^{b}$ & 0,148 & 0,014 \\
\hline
\end{tabular}

Médias na mesma linha seguidas da mesma letra minúscula não são estatisticamente diferentes $(P>0,05)$.

EPM - erro padrão da média.

TABELA 3 - Quantidade de CNE na base do colmo, para as alturas de pastejo em estudo, de julho/98 a março/99.

\begin{tabular}{lcccccc}
\hline Mês & $5 \mathrm{~cm}$ & $10 \mathrm{~cm}$ & $15 \mathrm{~cm}$ & $20 \mathrm{~cm}$ & Média & EPM \\
\hline & $-------------------\mathrm{kg} \mathrm{m}^{-2}---------------$ \\
Julho & $0,173^{\mathrm{ab}}$ & $0,200^{\mathrm{a}}$ & $0,147^{\mathrm{b}}$ & $0,165^{\mathrm{ab}}$ & 0,171 & 0,018 \\
Agosto & $0,166^{\mathrm{b}}$ & $0,191^{\mathrm{ab}}$ & $0,196^{\mathrm{a}}$ & $0,204^{\mathrm{a}}$ & 0,189 & 0,010 \\
Setembro & $0,194^{\mathrm{a}}$ & $0,262^{\mathrm{a}}$ & $0,207^{\mathrm{a}}$ & $0,272^{\mathrm{a}}$ & 0,232 & 0,041 \\
Outubro & $0,173^{\mathrm{b}}$ & $0,246^{\mathrm{a}}$ & $0,220^{\mathrm{a}}$ & $0,229^{\mathrm{a}}$ & 0,217 & 0,011 \\
Novembro & $0,216^{\mathrm{a}}$ & $0,229^{\mathrm{a}}$ & $0,208^{\mathrm{a}}$ & $0,160^{\mathrm{b}}$ & 0,203 & 0,014 \\
Dezembro & $0,165^{\mathrm{b}}$ & $0,212^{\mathrm{a}}$ & $0,215^{\mathrm{a}}$ & $0,238^{\mathrm{a}}$ & 0,207 & 0,013 \\
Janeiro & $0,130^{\mathrm{b}}$ & $0,218^{\mathrm{a}}$ & $0,176^{\mathrm{ab}}$ & $0,221^{\mathrm{a}}$ & 0,186 & 0,021 \\
Fevereiro & $0,123^{\mathrm{b}}$ & $0,163^{\mathrm{ab}}$ & $0,192^{\mathrm{a}}$ & $0,180^{\mathrm{a}}$ & 0,164 & 0,016 \\
Março & $0,141^{\mathrm{a}}$ & $0,151^{\mathrm{a}}$ & $0,140^{\mathrm{a}}$ & $0,161^{\mathrm{a}}$ & 0,148 & 0,016 \\
\hline
\end{tabular}

Médias na mesma linha seguidas da mesma letra minúscula não são estatisticamente diferentes $(P>0,05)$.

EPM - erro padrão da média.

TABELA 4 - Taxas de acúmulo de matéria seca de agosto/98 a março/99 para os cultivares de Cynodon spp.

\begin{tabular}{|c|c|c|c|c|c|}
\hline Mês & Tifton 85 & Florakirk & Coastcross & Média & EPM \\
\hline & \multicolumn{5}{|c|}{ 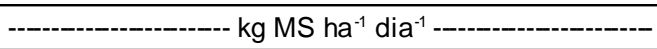 } \\
\hline Agosto & $27,8^{\mathrm{b}}$ & $37,5^{\mathrm{ab}}$ & $40,0^{\mathrm{a}}$ & 35,1 & 4,2 \\
\hline Setembro & $29,2^{\mathrm{ab}}$ & $24,5^{\mathrm{b}}$ & $35,3^{a}$ & 29,7 & 2,3 \\
\hline Outubro & $70,6^{\mathrm{a}}$ & $52,3^{a}$ & $70,1^{\mathrm{a}}$ & 64,3 & 6,9 \\
\hline Novembro & $57,1^{\mathrm{a}}$ & $38,2^{\mathrm{b}}$ & $50,7^{\mathrm{ab}}$ & 48,7 & 5,2 \\
\hline Dezembro & $104,3^{a}$ & $79,2^{\mathrm{b}}$ & $84,4^{\mathrm{ab}}$ & 89,3 & 7,3 \\
\hline Janeiro & $105,6^{a}$ & $90,1^{\mathrm{b}}$ & $90,6^{\mathrm{ab}}$ & 95,4 & 5,6 \\
\hline Fevereiro & $97,6^{a}$ & $71,9^{b}$ & $91,1^{\mathrm{a}}$ & 86,9 & 5,8 \\
\hline Março & $95,0^{a}$ & $88,3^{a}$ & $106,5^{a}$ & 96,6 & 8,2 \\
\hline
\end{tabular}

Médias na mesma linha seguidas da mesma letra minúscula não são estatisticamente diferentes $(P>0,05)$.

EPM - erro padrão da média. 
que, trabalhando concomitantemente na mesma área, obteve ganhos de peso vivo variando de 450 a 500 $\mathrm{kg} \mathrm{ha}^{-1}$ durante o período de agosto/98 a abril/99 (230 dias de pastejo).

Apesar de não terem sido observadas diferenças entre as alturas de pasto estudadas $(P>0,05)$, elas possivelmente existiram e não foram detectadas em função do método utilizado para determinação do acúmulo. Segundo Frame (1981), o método baseado em gaiola de exclusão tende a superestimar a quantidade de forragem nos pastos mais baixos e subestima-la nos pastos mais altos. Humphreys (1966), trabalhando com Panicum maximum var trichoglume, destacou que o crescimento foi independente da intensidade de desfolha, resultados esses semelhantes aqueles obtidos no presente experimento, onde não foi verificado o efeito da intensidade de pastejo sobre a taxa de acúmulo de matéria seca.

\section{CONCLUSÕES}

Os cultivares de Cynodon spp. apresentaram um padrão sazonal de alocação de CNE para os órgãos de reserva (base do colmo e raízes).

'Tifton-85' apresentou a maior quantidade (reserva) de CNE na base do colmo e raízes, o que poderia conferir a este cultivar uma maior tolerância a períodos de estresse.

Tifton-85 apresentou a maior produção de forragem no período experimental mas, no entanto, caracterizada por uma estacionalidade mais pronunciada que aquelas de Coastcross e Florakirk, respectivamente.

\section{AGRADECIMENTOS}

Aos integrantes do Grupo de Estudos com Plantas Forrageiras (GEPF) e à FAPESP (Fundação de Amparo à Pesquisa do Estado de São Paulo) pela concessão de bolsa de Mestrado e financiamento da pesquisa.

\section{REFERÊNCIAS BIBLIOGRÁFICAS}

ADEGBOLA, A.A.; MCKELL, C.M. Effect of nitrogen fertilization on the carbohydrate content of Coastal bermudagrass [Cynodon dactylon (L.) Pers.] Agronomy Journal, v.58, p.60-64, 1966.

ANDRADE, I.F.; MARQUES NETO, J. Efeito da carga animal sobre os níveis de carboidratos solúveis e pesos seco da base do colmo, base do caule e sistema radicular de Brachiaria decumbens. Revista da Sociedade Brasileira de Zootecnia, v.18, p.426-431, 1989.

BOKHARI, U.G. Regrowth of wertern wheatgrass utiling 14Clabelled assimilates stored in belowground parts. Plant and Soil, v.48, p.115-127, 1977.

BOTREL, M.A. Importância dos carboidratos de reserva e da preservação dos meristemas apicais na rebrota do capim jaraguá [Hyparrhenia rufa (Ness) Stapf]. Viçosa, 1980. 41p. Dissertação (M.S.) - Universidade Federal de Viçosa.

BRASIL. Ministério da Agricultura. Serviço Nacional de Pesquisa Agronômica. Comissão de Solos. Levantamento de reconhecimento dos solos do estado de São Paulo. Rio de Janeiro, 1960. 634p. (Boletim, 12).
BROUGHAM, R.M. Effects of intensity of defoliation on regrowth of pastures. Australian Journal of Agricultural Research, v.7, p.377-387, 1956.

CARNEVALLI, R.A. Desempenho de ovinos e respostas de pastagens de Cynodon spp submetidas a regimes de desfolha sob lotação contínua. Piracicaba, 1999. 90p. Dissertação (Mestrado) - Escola Superior de Agricultura "Luiz de Queiroz", Universidade de São Paulo.

CARVALHO, C.A.B. Padrões demográficos de perfilhamento e acúmulo de forragem em pastagens de Cynodon spp. manejadas em quatro intensidades de pastejo. Piracicaba, 2000. 96p. Dissertação (Mestrado) - Escola Superior de Agricultura "Luiz de Queiroz", Universidade de São Paulo.

DAVIES, A.; FORTHERGILL, M.; MORGAN, C.T. Assesment of contrasting perennial ryegrass, with and without white clover, under continuous sheep stoking in the uplands. 5. Herbage production, quality and intake in years 4-6. Grass and Forage Science, v.48, p.213-222, 1993.

DUNN, J.H.; NELSON, C.J. Chemical changes occuring in three bermudagrass turf cultivars in relation to cold hardiness. Agronomy Journal, v.66, p.28-31, 1974.

FAGUNDES, J.L.; Da SILVA, S.C.; PEDREIRA, C.G.S.; SBRISSIA, A.F.; CARNEVALLI, R.A.; CARVALHO, C.A.B.; PINTO, L.F.M. Efeito de intensidades de pastejo sobre o índice de área foliar, interceptação luminosa e acúmulo de forragem em pastagens de Cynodon spp. Scientia Agricola, v.56, p.1141-1150, 1999.

FRAME, J. Herbage mass. In: HODGSON, J.; BAKER, R.D.; DAVIES, A.; LAIDLAW, A.S.; LEAVER, J.D. (Ed.) Sward measurement handbook. Berkshire: British Grassland Society, 1981. cap.3, p.39-67.

GEORGE, J.R.; OBERMANN, D.J.; WOLF, D.D. Seazonal trends for nonstructural carbohydrates in stem bases of defoliated switchgrass. Crop Science, v.29, p.1282-1287, 1989.

GOMIDE, J.A.; OBEID, J.A.; RODRIGUES, L.R.A. Fatores morfofisiológicos de rebrota do capim-colonião (Panicum maximum). Revista da Sociedade Brasileira de Zootecnia, v.8, p.532-562, 1979

GROSS, C.D. Efeitos do desfolhamento sobre os níveis das frações nitrogenadas, carboidratos e fenóis solúveis em raízes de braquiária (Brachiaria decumbens, Stapf). Piracicaba, 1988. 97p. Dissertação (Mestrado) - Escola Superior de Agricultura "Luiz de Queiroz", Universidade de São Paulo.

HUMPHREYS, L.R. Subtropical grass growth: II Effects of variation in leaf area index in the field. Queensland Journal of Agricultural and Animal Science, v.23, p.358-388, 1966.

HUMPHREYS, L.R. Effects of defoliation on the growth of tropical pastures. In: HUMPHREYS, L.R. (Ed.) Tropical pasture utilization. Cambridge: Cambridge University Press, 1991. cap.4, p.46-65.

JONES, C.A.; CARABALY, A. Some characteristics of the regrowth of 12 tropical grasses. Tropical Agriculture Trinidad, v.58, p.37-44, 1981.

LEMAIRE, G.; AGNUSDAI, M. Leaf tissue turnover and efficiency of herbage utilization. In: INTERNATIONAL SYMPOSIUM GRASSLAND ECOPHYSIOLOGY AND GRAZING ECOLOGY, 1., Curitiba, 1999. Anais. Curitiba: UFPR, 1999. p.165-183.

MARASCHIN, G.E. Manejo de "Coast-cross-1" sob pastejo. In: WORKSHOP SOBRE O POTENCIAL FORRAGEIRO DO GÊNERO CYNODON, Juiz de Fora, 1996. Anais. Juiz de Fora: EMBRAPA,CNPGL, 1996. p.93-110.

MAY, L.H. The utilization of carbohydrate reserves in pasture plants after defoliation. Herbage Abstracts, v.30, p.239-245, 1960.

OMETTO, J.C. Registros e estimativas dos parâmetros meteorológicos da região de Piracicaba, SP. Piracicaba: FEALQ, 1989. 76p. 
PAULA, R.R.; GOMIDE, J.A.; SYKES, D.; CHAVES, J.R. Influência de diferentes sistemas de corte sobre o desenvolvimento radicular do capim gordura. Revista Ceres, v.16, p.10-18, 1969.

PEDREIRA, C.G.S. Plant and animal responses on grazed pastures of 'Florakirk' and 'Tifton-85' bermudagrasses. Gainesville, 1995. 153p. Thesis (Ph.D.) - University of Florida.

REIS, R.A.; GARCIA, J.A.; GOMIDE, J.A.; OBEID, J.A. Efeito dos regimes de corte nos níveis de carboidratos totais nãoestruturais do capim-braquiária (Brachiaria decumbens Stapf.). Revista da Sociedade Brasileira de Zootecnia, v.14, p.522-528, 1985.

RODRIGUES, L.R.A.; RODRIGUES, T.J.D. Ecofisiologia de plantas forrageiras. In: CASTRO, P.R.C.; FERREIRA, S.O.; YAMADA, T. (Ed.) Ecofisiologia da produção agrícola. Piracicaba: POTAFOS, 1987. cap.12, p.203-230.

SAS INSTITUTE. SAS user's guide: release 6.03. Cary: Statistical Analysis System Institute, 1988. 1028p.

SBRISSIA, A.F. Compensação tamanho/densidade populacional de perfilhos em pastagens de Cynodon spp. Piracicaba, 2000. 80p. Dissertação (Mestrado) - Escola Superior de Agricultura "Luiz de Queiroz", Universidade de São Paulo.

SILVA, D.J. Carboidratos totais não estruturais (CNT). In: SILVA, D.J. (Ed.) Análise de alimentos: métodos químicos e biológicos. Viçosa: Imprensa Universitária, 1990. cap.13, p.103-108.
SMITH, D. Removing and analysing total nonstructural carbohydrates from plant tissue. Wisconsin Agricultural Eperimental Station Research Report, v.41, p.1-11, 1969.

SMITH, D. Carbohydrate reserves of grasses. In: YOUNGNER, V.B.; McKELL, C.M. (Ed.) The biology and utilization of grasses. New York: Academic Press, 1972. cap.23, p.318331.

SMITH, D. The nonstructural carbohydrates. In: BUTLER, G.W.; BAILEY, R.W. (Ed.) Chemistry and biochemistry of herbage. London: Academic Press, 1973. cap.3, p.105-155.

SMITH, D.; GROTELUESCHEM, R.D. Carbohydrates in grasses: I. Sugar and fructosan composition of the stem bases of several northern-adapted grasses at seed maturity. Crop Science, v.6, p.263-266, 1966.

SOARES FILHO, C.V. Variação sazonal de parâmetros bioquímico-fisiológicos em braquiária decumbens estabelecida em pastagem. Piracicaba, 1991. 110p. Dissertação (Mestrado) - Escola Superior de Agricultura "Luiz de Queiroz", Universidade de São Paulo.

STRYER, L. Biochemistry. Stanford: Stanford University Press, 1975. p.881.

WEINMANN, H. Total available carbohydrates in grasses and legumes. Herbage Abstracts, v.31, p.255-261, 1961.

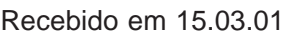

